7. Reprod. Fert. (1966) 12, 539-550

\title{
LOCAL MAINTENANCE OF THE CORPUS LUTEUM IN SHEEP WITH EMBRYOS TRANSFERRED TO VARIOUS ISOLATED PORTIONS OF THE UTERUS
}

\author{
R. M. MOOR AND L. E. A. ROWSON \\ A.R.C. Unit of Reproductive Physiology and Biochemistry, \\ University of Cambridge*
}

(Received 4th June 1966)

Summary. The relationship between the embryo and the corpus luteum was investigated by transferring embryos to various isolated portions of the uteri of 115 non-pregnant recipient ewes allocated to four experiments.

Embryos transferred to sheep with intact uteri (Experiment 1) were shown to be capable of maintaining the corpus luteum irrespective of whether they were transferred to the uterine horn adjacent to the corpus luteum (ipsilateral horn) or to the horn on the opposite side of the corpus luteum (contralateral horn.)

Embryos transferred to sheep with one surgically isolated uterine horn (Experiment 2) maintained luteal function only in the ovary adjacent to the gravid horn. Thus, embryos placed in the isolated ipsilateral uterine horn maintained luteal function in $80 \%$ of the recipients, while embryos transferred to the isolated contralateral horn had no effect on the life-span of the corpus luteum. However, if the ipsilateral horn was removed, embryos transferred to the contralateral horn regularly maintained the life-span of the corpus luteum during pregnancy.

Embryos transferred to one isolated horn of recipient ewes that had corpora lutea in both ovaries (Experiment 3) further confirmed the existence of a local unilateral relationship between the embryo and the corpus luteum: since only the corpora lutea adjacent to the gravid horn were maintained.

Embryos transferred to the isolated ovarian half of the ipsilateral horn (Experiment 4) maintained luteal function in 30\% of the recipients. Embryos placed in the isolated cervical half of the ipsilateral horn or in the ovarian half of the contralateral horn did not prevent regression of the corpus luteum at the 15th day.

These results are interpreted to signify that the embryo overcomes the lytic effect of the uterus in a local manner. It would appear that the

* Postal address: Animal Research Station, 307 Huntingdon Road, Cambridge. 
life-span of corpora lutea in sheep with ligated uteri is primarily regulated by the relative position of the lytic non-gravid horn and the corpus luteum, and not by the position of the pregnant horn as such.

\section{INTRODUCTION}

In the sheep, regression of the corpus luteum on the 15th day of the cycle is the result of a lytic effect from the non-pregnant uterus (Wiltbank \& Casida, 1956; Moor \& Rowson, 1964) The exact nature of this effect is unknown, but experiments have shown that the uterus influences the corpus luteum in a local manner, such that each ovary is initially affected only by the adjacent uterine horn (Moor \& Rowson, 1966a). Furthermore it has been shown that the lytic effect of the uterus is overcome by the embryo, even when embryos are placed in the uterus as late as the 12th day after oestrus (Moor \& Rowson, $1966 \mathrm{~b}, \mathrm{c})$.

The object of the present experiments has been to determine whether the embryo overcomes the lytic influence of the uterus in a local or generalized manner. In order to study this, a technique was used whereby embryos were transferred to isolated segments of the uteri of non-pregnant ewes.

\section{METHODS}

A total of 214 sheep of the Welsh Mountain and Suffolk breeds were used in four experiments; ten ewes were used as controls, eighty-nine as donors of embryos and 115 as recipients. The work was carried out between 1964 and 1966 and during each breeding season the sheep were kept under the same conditions as were described elsewhere (Moor, 1965). The onset of oestrus (Day 0 ) was detected to the nearest $12 \mathrm{hr}$ by using a raddled vasectomized ram. The mean length of the oestrous cycles in the flock from which the experimental animals were randomly drawn was 16.6 $\pm 0 \cdot 2$ days.

The techniques used in the donor ewes for superovulation, mating and the recovery of embryos have been described previously (Moor \& Rowson, 1966b). Anaesthesia and laparotomy were carried out in a similar manner to that described by Deane, Hay, Moor, Rowson \& Short (1966). The corpora lutea in the recipient ewes were marked with India ink and their number and position on the ovaries were recorded. Only one corpus luteum was present in each of the recipients allocated to Experiments 1,2 and 4; two or more corpora lutea were present in each of the recipients allocated to Experiment 3.

Two embryos were transferred to each recipient ewe according to the method of Hunter, Adams \& Rowson (1955). Transfers were carried out only when the onset of oestrus in the donor and recipient sheep was synchronized to within $12 \mathrm{hr}$. After transplantation of the embryos, recipients were again placed with vasectomized rams and the occurrence of any post-operative oestrous cycles was recorded.

For clarity the following terms will be used. The 'isolated' uterine horn or segment was that section of the uterus which was ligated and separated from 
the rest of the uterus. It was not separated from the fallopian tube. The 'ipsilateral uterine horn' refers to the horn on the same side as the ovary containing the corpus luteum. The 'contralateral uterine horn' refers to the horn on the opposite side to the corpus luteum. The term 'embryo' is used in its widest sense to describe both the embryo proper and the embryonic membranes.

Four separate experiments were carried out as follows.

\section{Experiment 1}

The object of this experiment was to determine if, in sheep with normal intact uteri, there was any difference between transferring embryos to the ipsilateral or to the contralateral uterine horn. The twenty recipients in Experiment 1 were divided into two groups.

Group I. Two 5-day or two 9-day embryos (i.e. embryos recovered from donors on Day 5 or 9) were transferred to the ipsilateral uterine horn in each of twelve recipient ewes.

Group II. Two 5-day or 9-day embryos were transferred to the contralateral uterine horn in each of eight recipient ewes.

All the recipients in Experiment 1 that had not returned to oestrus by Day 25 were autopsied, the ovaries were examined for corpora lutea and the uteri opened and the contents recorded.

\section{Experiment 2}

The purpose of this experiment was to determine the effect on luteal function of embryos placed in one isolated uterine horn of non-pregnant recipient sheep. One horn was isolated by placing two silk ligatures $1 \mathrm{~cm}$ apart around the horn just above its junction with the body of the uterus; particular care was taken to avoid constricting the visible large uterine blood vessels. The uterine horn was then severed between the ligatures to ensure its complete isolation from the remainder of the uterus.

The thirty-five recipients in Experiment 2 were divided into three groups.

Group I. Two 5-day embryos were transferred to the isolated ipsilateral horn in each of ten recipients.

Group II. Two 5-day embryos were transferred to the isolated contralateral horn in each of fifteen recipients.

Group III. Two 5-day embryos were transferred to the isolated contralateral horn in each of ten recipients, but the ipsilateral uterine horn was completely removed at the same time as the transfer.

Half the ewes that did not return to oestrus by Day 25 in each of these groups were autopsied, the ovaries were examined for corpora lutea and the uteri opened and the contents recorded. The remaining pregnant sheep were examined by laparotomy on Day 25 and then autopsied on either Day 50 or Day 100.

\section{Experiment 3}

Whereas, in the preceding two experiments, each recipient had only one corpus luteum, this experiment was designed to include animals with one or 
more corpora lutea in each ovary. This was done to test whether the embryo exerts a similar effect on the two ovaries of the same sheep.

The ten recipients in Experiment 3 were divided into two groups.

Group I. Two 5-day embryos were transferred to one isolated uterine horn in each of five recipients which all had one naturally formed corpus luteum on each ovary.

Group II. Two 5-day embryos were transferred to one isolated uterine horn in each of five superovulated recipients which all had more than one corpus luteum on each ovary. Superovulation was induced by injecting 1000 i.u. of pregnant mare's serum (PMs)/animal on Day 13 of the cycle prior to transfer.

Those recipients that had not shown oestrus by Day 25 were subjected to laparotomy and a heparinized syringe was used to aspirate a $20 \mathrm{ml}$ sample of blood from the major vein draining each ovary. The recipients were then killed, the ovaries dissected and fixed in Bouin's fluid and the uteri opened and the contents recorded.

The ovarian venous blood collected from animals in both groups was used for the determination of progesterone concentration; this was carried out by the method of Short (1958), with the exception that the step which involves partition between light petroleum and $70 \%$ aqueous methanol was omitted. $\left[7-{ }^{3} \mathrm{H}\right]$ Progesterone $(0.007 \mu \mathrm{g}, 0.05 \mu \mathrm{c})$ was included as an internal recovery standard in order to correct for extraction losses which were in the range of $25 \%$ to $35 \%$. The results of the progesterone analyses are exposed in a corrected form.

\section{Experiment 4}

The purpose of this experiment was to determine the life-span of corpora lutea in ewes with embryos placed in an isolated segment of one uterine horn.

The fifty recipients in Experiment 4 were divided into three groups.

Group I. Two 5-day or two 9-day embryos were transferred to the isolated ovarian half of the ipsilateral uterine horn in each of twenty recipients.

Group II. Two 5-day or two 9-day embryos were transferred to the ovarian half of the contralateral uterine horn in each of twenty recipients.

Group III. The ovarian half of the ipsilateral uterine horn was isolated in a further ten recipients. However, in this group two 5-day embryos were transferred to the intact three-quarters of the uterus, thus leaving the isolated ipsilateral segment empty.

All the recipients that had not returned to oestrus by Day 25 were autopsied, their ovaries were examined for corpora lutea and their uteri opened and the contents recorded.

The treatments carried out in the four experiments are summarized in Text-fig. 1.

In addition to the above experimental animals ten ewes were included as controls. On the 5th day of the cycle ligation of the ipsilateral uterine horn was carried out in five ewes and the contralateral horn was ligated in the other five animals. No further treatment was given, but the length of the postoperative oestrous cycles was recorded. 


\section{RESULTS}

Isolation of one uterine horn by ligation had no detectable effect on the length of the first post-operative oestrous cycle in any of the ten non-pregnant control sheep.

The results obtained in the four experiments described above were as follows.

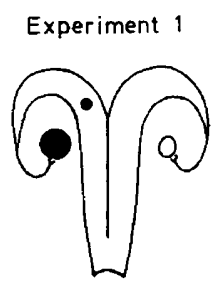

Group I

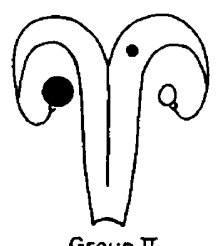

Group II

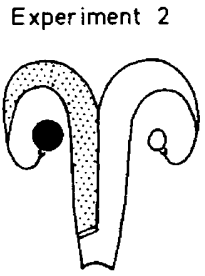

Group I
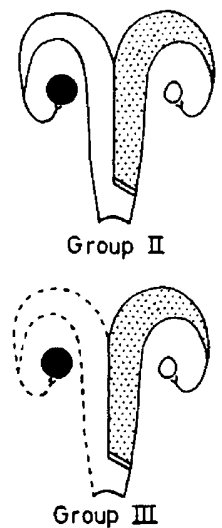

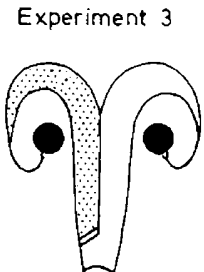

Group 1
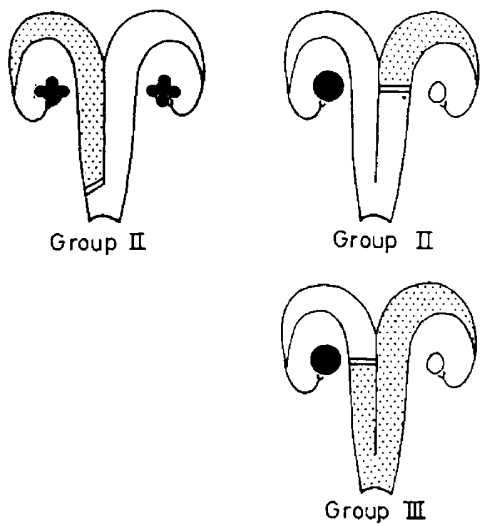

TEXT-FIc. 1. A diagrammatic representation of the reproductive tracts of the various groups of sheep comprising the four experiments.

The intra-uterine black dot in Experiment 1 indicates the site of deposition of the embryos. The shaded uterine area in the other experiments represents that isolated portion of the uterus to which embryos were transferred. The ovary bearing the corpus luteum is blackened and its relationship to the gravid horn is shown. The broken line (Experiment 2, Group III) shows the portion of the uterus which was removed.

\section{Experiment 1}

The life-span of the corpus luteum after the transfer of embryos to either the ipsilateral or contralateral uterine horn of sheep with intact normal uteri is shown in Table 1.

There was no significant difference between Group I and Group II in respect of the number of normal pregnancies that resulted from the transfer of embryos on Day 5 and Day 9. Furthermore, it clearly makes no difference in ewes with intact uteri whether the embryos are deposited on the same side as the corpus luteum or on the opposite side: in Group I, corpora lutea of pregnancy were maintained in $75 \%$ of the ewes (nine out of twelve) following the transfer of embryos to the ipsilateral horn. In Group II, the corpora lutea were maintained in $63 \%$ of the recipients (five out of eight) following the transfer of embryos to the contralateral horn. 


\section{Experiment 2}

Table 2 shows the effect on the life-span of the corpus luteum of embryos transferred to one isolated uterine horn of non-pregnant recipients.

The corpora lutea in eight out of ten recipients in Group I were maintained in a fully functional state during pregnancy by embryos placed in the isolated ipsilateral uterine horn. The normal function of the corpora lutea was indicated by a progesterone concentration in the luteal tissue of the eight pregnant ewes

\section{TABLE 1}

EXPERIMENT I : THE LIFE-SPAN OF THE CORPUS LUTEUM FOLLOWING THE TRANSFER OF TWO EMBRYOS TO EITHER THE IPSILATERAL OR CONTRALATERAL UTERINE HORN OF RECIPIENT SHEEP WITH NORMAL INTACT UTERI

\begin{tabular}{c|c|c|c|c}
\hline $\begin{array}{c}\text { Site of embryo } \\
\text { transfer relative } \\
\text { to side of } \\
\text { corpora lutea }\end{array}$ & $\begin{array}{c}\text { No. of } \\
\text { days from } \\
\text { oestrus to } \\
\text { transfer }\end{array}$ & $\begin{array}{c}\text { No. of } \\
\text { recipients) } \\
\text { group }\end{array}$ & $\begin{array}{c}\text { No. of } \\
\text { receipients } \\
\text { pregnant } \\
\text { at autopsy } \\
\left(\begin{array}{c}\text { Day } \\
25)\end{array}\right.\end{array}$ & $\begin{array}{c}\text { No. of recipients that } \\
\text { returned to oestrus after } \\
\text { transfer with: }\end{array}$ \\
\hline $\begin{array}{c}\text { Normal cycle } \\
(<19 \text { days })\end{array}$ & $\begin{array}{c}\text { Extended cycle } \\
(>19 \text { days })\end{array}$ \\
\hline
\end{tabular}

The experimental procedure in two groups of sheep is shown diagrammatically: the black dot depicts the uterine site to which the embryos were transferred. The blackened ovary represents the ovary containing the corpus luteum.

of 33 to $55 \mu \mathrm{g} / \mathrm{g}$ of tissue. One of the two ewes in Group I that did not remain pregnant had an extended cycle of 20 days while an unmarked corpus luteum was found in the other sheep at autopsy on Day 25: this signifies that in the latter animal a new ovulation had occurred.

From the results obtained in Group I it was clear that neither the presence of ligatures on the ipsilateral horn nor the isolation of embryos in that horn significantly affected the ability of those embryos to develop and maintain luteal function during pregnancy.

By contrast embryos placed in the contralateral uterine horn (Group II) were entirely unable to maintain the life-span of the corpus luteum. In this group, none of the fifteen ewes became pregnant and in at least thirteen of them the corpus luteum regressed at the end of the normal oestrous cycle. In only two animals in this group was there even a possible effect of the embryo on the 
corpus luteum; one ewe was found to have an unmarked corpus luteum at autopsy on Day 25 (signifying a recent ovulation), while the second animal returned to oestrus on Day 22.

In Group III it was demonstrated that if the ipsilateral horn was removed, embryos transferred to the contralateral horn developed and maintained the life-span of the corpus luteum during pregnancy in nine out of ten recipients.

TABLE 2

EXPERIMENT 2: THE EFFECT ON THE LIFE-SPAN OF THE CORPUS LUTEUM OF EMBRYOS TRANSFERRED TO ONE ISOLATED UTERINE HORN OF NON-PREGNANT RECIPIENT EWES

\begin{tabular}{|c|c|c|c|c|}
\hline \multirow{2}{*}{$\begin{array}{l}\text { Position of isolated } \\
\text { gravid horn (shaded) } \\
\text { relative to the side } \\
\text { of the corpus luteum }\end{array}$} & \multirow{2}{*}{$\begin{array}{l}\text { No. of } \\
\text { recipients/ } \\
\text { group }\end{array}$} & \multirow{2}{*}{$\begin{array}{l}\text { No. of } \\
\text { recipients } \\
\text { pregnant } \\
\text { at autopsy } \\
\text { (Day 25) }\end{array}$} & \multicolumn{2}{|c|}{$\begin{array}{l}\text { No. of recipients that } \\
\text { retumed to oestrus after } \\
\text { transfer with: }\end{array}$} \\
\hline & & & $\begin{array}{l}\text { Normal cycle } \\
(<19 \text { days })\end{array}$ & $\begin{array}{c}\text { Extended cycle } \\
(>19 \text { days })\end{array}$ \\
\hline & 10 & 8 & 0 & 2 \\
\hline & 15 & 0 & 13 & 2 \\
\hline & 10 & 9 & 0 & 1 \\
\hline
\end{tabular}

The experimental procedure in the three groups of sheep is shown diagrammatically: the shaded area represents that portion of the uterus to which the two 5-day embryos were transferred. The ablated ipsilateral uterine horn in Group III is indicated by broken lines. The ovary containing the corpus luteum is shown in each diagram as the blackened ovary.

This observation is particularly interesting since it indicates that the embryo or some accompanying factor must have access to the ipsilateral horn in order to overcome the lytic effect of that horn.

\section{Experiment 3}

Table 3 shows the function and life-span of corpora lutea situated on the two ovaries of the same sheep following the transfer of embryos to one isolated uterine horn.

The number of recipients with maintained corpora lutea was very similar in 


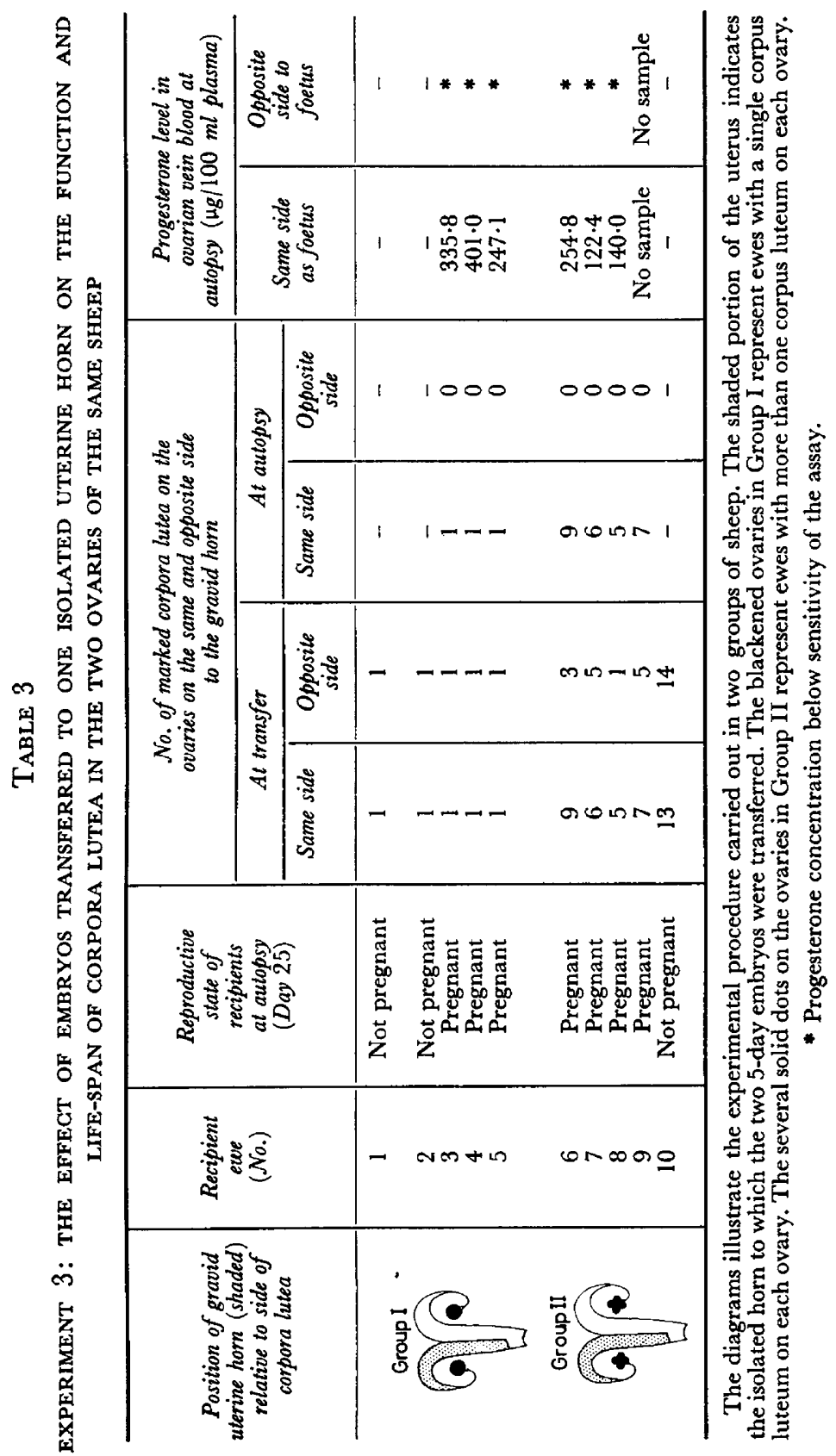


the two groups, namely three out of five in Group I and four out of five in Group II. Striking functional differences were, however, observed between the corpora lutea on the two ovaries of each of the pregnant recipients. These functional differences are clearly reflected by levels of progesterone. Thus, all the corpora lutea that were present in the ovary adjacent to the gravid horn

TABLE 4

EXPERIMENT 4: THE EFFECT ON THE LIFE-SPAN OF THE CORPUS LUTEUM OF EMBRYOS TRANSFERRED TO AN ISOLATED SEGMENT OF THE UTERUS OF NONPREGNANT REGIPIENT EWES

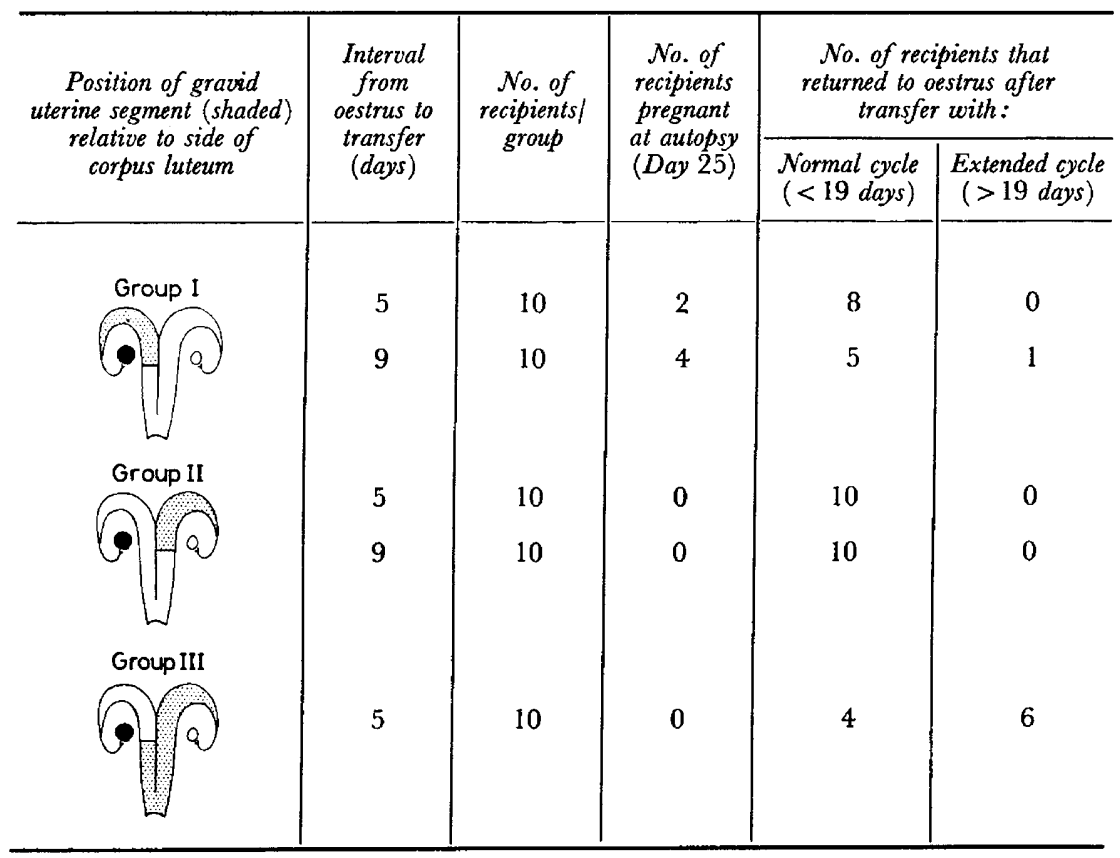

The diagrams illustrate the experimental procedure carried out in three groups of sheep. The shaded portion of the uterus indicates the segment to which two embryos were transferred. The blackened ovary in each diagram represents the ovary containing the corpus luteum.

were found to be in a fully functional state. In contrast, complete regression of all the corpora lutea had occurred in the contralateral ovary.

The results of Experiment 3 demonstrate clearly that the embryo overcomes the lytic effect of the uterus in a local manner. Embryos confined to one uterine horn by ligation were unable to prevent luteal regression in the ovary adjacent to the sterile horn.

\section{Experiment 4}

Table 4 shows the effect on the life-span of the corpus luteum of embryos transferred to an isolated segment of the uterus.

In Group I the presence of embryos in the ovarian half of the ipsilateral horn 
did not prevent normal luteal regression at the end of the oestrous cycle in thirteen out of twenty recipients. However, the corpora lutea in six out of the seven remaining recipients were maintained in the normal manner during pregnancy. These results are of interest since they show, firstly, that embryos placed in the ovarian half of the ipsilateral horn allowed either normal pregnancy to continue or caused luteal regression on Day 15. Secondly, it was noted that the percentage of maintained corpora lutea in this group $(30 \%)$ was slightly less than half that obtained by transferring embryos to the entire ipsilateral horn (Experiment 2, Group I).

The results in Group II showed clearly that embryos transferred to the ovarian half of the contralateral horn had no effect on the corpora lutea of any of the twenty recipients.

None of the recipients in Group III were found to be pregnant at autopsy on Day 25. Nevertheless, the life-span of the corpora lutea in six out of the ten recipients was significantly extended following embryo transfer.

\section{DISCUSSION}

Previous experiments have demonstrated that local uterine mechanisms are involved in the termination of luteal function in the cyclical sheep (Moor \& Rowson, 1966a). The present experiments show conclusively that the effect of the embryo in maintaining the life-span of the corpus luteum during early pregnancy is also local in nature. This conclusion is similar to that drawn from the results of experiments involving unilateral pregnancies in the pig ( $\mathrm{Du}$ Buisson, 1961; Anderson, Ratchmacher \& Melampy, 1966).

The following facts about the mechanism underlying the relationship between the embryo and the corpus luteum in the sheep are suggested by our experimental results. The most important finding was obtained by placing embryos in one isolated uterine horn of otherwise normal recipient sheep. This demonstrated that the isolated embryo is able to maintain luteal function only in the ovary adjacent to the gravid horn. Thus, embryos transferred to the isolated ipsilateral horn maintained the life-span of the corpus luteum during pregnancy, while those placed in the contralateral horn had no significant effect on luteal function. Isolation of the gravid horn by ligation, therefore, clearly prevented the embryo from overcoming the lytic effect of the non-gravid horn.

The second main conclusion drawn from these experiments was derived from the fact that embryos placed in the contralateral horn regularly maintained luteal function during pregnancy provided that the non-gravid ipsilateral uterine horn was removed at the time of embryo transfer. From these findings it is evident that the life-span of the corpora lutea in the experimental sheep was primarily regulated by the relative positions of the non-gravid horn and the corpus luteum: the exact position of the gravid horn was not in itself a critical factor in maintaining the life-span of the corpora lutea. Our experiments do not clearly indicate whether the effect of the embryo is 'anti-luteolytic' or directly 'luteotrophic' in nature, but in the light of both the above results and those obtained previously (Moor \& Rowson, 1966b, c) it is suggested that an 'anti-luteolytic' effect of the early embryo is the more probable mode of action. 
A comparison of the present results with those obtained in earlier experiments (Moor \& Rowson, 1966a) shows that the life-span of corpora lutea in unilaterally hysterectomized sheep is different from that observed in unilaterally pregnant recipients. It has been demonstrated that the removal of the ipsilateral uterine horn in non-pregnant ewes maintains luteal function for an average of about 17 days beyond the normal cyclical life-span of the corpus luteum (Moor \& Rowson, 1966a). The ultimate regression of the corpora lutea in the unilaterally hysterectomized ewes was found to be due to the presence of the non-gravid contralateral horn. The presence of the non-gravid contralateral horn in unilaterally pregnant recipients, on the other hand, clearly did not cause luteal regression in the recipients for at least the first 100 days of pregnancy (ewes autopsied at that stage). This suggests that the essentially local effect of the early embryo on the corpus luteum changes to a more generalized effect later in pregnancy. Similar findings have been obtained by Du Buisson \& Rombauts (1963) in work involving the experimental reduction of the number of embryos in pregnant pigs. These workers concluded from their results that a portion of empty uterine horn has a lytic effect on luteal function during the first 40 days of pregnancy. However, after Day 40 of pregnancy the uterine luteolytic influence of a segment of empty uterine horn was no longer generally apparent.

The results of Experiment 4 show that embryos placed in the isolated ovarian half of the ipsilateral horn maintained the life-span of the corpora lutea more efficiently than embryos transferred to the cervical half of the same horn. It is thus possible that each part of the uterine horn affects luteal function in the adjacent ovary to a different extent; this effect is probably largely governed by the anatomical relationship between that particular portion of the uterus and the adjacent ovary.

Embryos transferred to sheep with intact uteri were found to be capable of maintaining the life-span of the corpus luteum irrespective of where the embryos were placed in the uterus. A recent experiment by Niswender \& Dziuk (1966) has confirmed this observation and has further shown that a single embryo can maintain luteal function in both ovaries of the normal ewe. From these results it is evident that the embryo can overcome the lytic effect of both uterine horns irrespective of its exact position in the uterus.

The results of the control experiment showed that the presence of uterine ligatures did not affect luteal function in the first post-operative oestrous cycle. Laparotomies carried out in those ewes indicated that the isolated uterine horn did not fill with fluid until after the sheep had returned to oestrus. That the uterine ligatures did not in themselves hinder the normal development of transferred embryos was clearly shown by the high percentage of maintained pregnancies that resulted from transfers to the isolated ipsilateral horn.

In summary, it is suggested that the lytic effect of the ovine uterus can be overcome by the embryo under the following circumstances. Firstly, the embryo must be in the uterus by the 12th day after oestrus, and secondly, the embryo or its secretions must have access to the uterine horn adjacent to the corpus luteum. Furthermore, it is probable that the local relationship that exists between the embryo and the corpus luteum during early pregnancy changes later into a more generalized placental luteotrophic effect. 


\section{ACKNOWLEDGMENTS}

We are grateful to Dr J. S. Perry and Dr R. V. Short for reading this manuscript, and to $\mathrm{Mr} \mathrm{W}$. D. Booth for carrying out the progesterone determinations. We thank Dr T. R. R. Mann, F.R.s., for his interest and advice.

\section{REFERENCES}

Anderson, L. L., Ratchmacher, R. P. \& Melampy, R. M. (1966) The uterus and unilateral regression of corpora lutea in the pig. Am. 7. Physiol. 210, 611.

Deane, H. W., Hay, M. F., Moor, R. M., Rowson, L. E. A. \& Short, R. V. (1966) The corpus luteum of the sheep: relationships between morphology and function during the oestrous cycle. Acta endocr., Copenh. 51, 245.

Du Bursson, F. Du M. (1961) Possibilités d'un fonctionnement dissemblable des ovaires pendant la gestation chez la truie. C.r. hébd. Seanc. Acad. Sci., Paris, 253, 727.

Du Buisson, F. Du M. \& Rombauts, P. (1963) Reduction experimentale du nombre des foetus au cours de la gestation de la truie et maintien des corps jaunes. Annls Biol. anim. Biochem. Biophys. 3, 445.

Hunter, G. L., Adams, C. E. \& Rowson, L. E. A. (1955) Interbreed ovum transfer in sheep. F. agric. Sci. 46, 143.

Moor, R. M. (1965) The corpus luteum of the sheep. Thesis, Cambridge University.

Moor, R. M. \& Rowson, L. E. A. (1964) Influence of the embryo and uterus on luteal function in the sheep. Nature, Lond. 201, 522.

Moor, R. M. \& Rowson, L. E. A. (1966a) Local uterine mechanisms affecting luteal function in the sheep. F. Reprod. Fert. 11, 307.

Moor, R. M. \& Rowson, L. E. A. (1966b) The corpus luteum of the sheep: functional relationships between the embryo and the corpus luteum. F. Endocr. 34, 233.

Moor, R. M. \& Rowson, L. E. A. (1966c) The corpus luteum of the sheep: effect of the removal of embryos on luteal function. . Endocr. 34, 497.

Niswender, G. D. \& Dziuk, P. J. (1966) A study of the unilateral relationship between the embryo and the corpus luteum by egg transfer in the ewe. Anat. Rec. 154, 394.

Short, R. V. (1958) Progesterone in blood. I. The chemical determination of progesterone in peripheral blood. 7. Endocr. 16, 415.

Wiltbank, J. N. \& Casida, L. E. (1956) Alteration of ovarian activity by hysterectomy. F. Anim. Sci. 15, 134 . 